\title{
Green synthesis of silver nanoparticles and assay of their antibacterial activity
}

\author{
Uzma Batool $^{1}$, Nadia Jabbar ${ }^{1}$, Sadaf Shaheen ${ }^{1}$, Muhammad Shahid \\ Rafique $^{2}$ and Iqra Arooj ${ }^{1 *}$ \\ 1. Department of Microbiology and Molecular Genetics, The Women University, Multan, Pakistan \\ 2. Institute of Applied Microbiology, University of Veterinary and Animal Sciences, Lahore, Pakistan \\ *Corresponding author's email: iqra.6051@wum.edu.pk \\ Citation \\ Uzma Batool, Nadia Jabbar, Sadaf Shaheen, Muhammad Shahid Rafique and Iqra Arooj. Green synthesis of silver \\ nanoparticles and assay of their antibacterial activity. Pure and Applied Biology. Vol. 11, Issue 2, pp386-396. \\ http://dx.doi.org/10.19045/bspab.2022.110038
}

Received: 17/04/2021 Revised: 19/06/2021

Accepted: 26/06/2021

Online First: 27/07/2021

\section{Abstract}

Nanoparticles have gained considerable attention in recent era among which, silver nanoparticles (AgNPs) have demonstrated exceptional characteristics in medical sciences, particularly. Use of plants for AgNP synthesis represents an eco-friendly, low cost and energy-efficient approach to combat microbial diseases and growing antibiotic resistance. The present study aimed at synthesizing AgNPs using extracts of Aloe vera peel as well as Ranunculus paludosus and Matthiola incana flowers and assessment of their antibacterial potential against clinically isolated multi-drug resistant (MDR) bacteria. The biocidal potential of crude extracts as well as synergistic action of crude extracts and selected antibiotics was determined by Kirby-Bauer disk diffusion method. Results showed that crude extracts alone or with selected antibiotics showed no antibacterial potential against MDR pathogens including Proteus vulgaris, Pseudomonas aeruginosa, Escherichia coli, Staphylococcus aureus and Klebsiella pneumoniae. AgNPs were synthesized by addition of silver nitrate solution to crude extracts. UV-Visible spectroscopy analysis was done to confirm the synthesis of AgNPs while Fourier transform infrared (FTIR) spectroscopy analysis was performed to depict the functional groups associated with formation of AgNPs. Antimicrobial activity of synthesized AgNPs alone and their synergistic activity with selected antibiotics was then estimated. Results demonstrated the biocidal effectiveness of synthesized AgNPs against MDR pathogens which was further enhanced when used in combination with antibiotics as depicted by wide and clear zones of inhibition. These observations are suggestive of promising antibacterial activity of Aloe vera peel as well as flowers of Ranunculus paludosus and Matthiola incana which may be further validated by extensive research. Keywords: Antibiotics; Biocidal action; Multidrug resistant pathogens

\section{Introduction}

Nanotechnology as an advance emerging field of science, deals in particles with large surface area and small size ranging from 1 to $100 \mathrm{~nm}$ [1]. Several unique aspects are attributable towards the nanoparticles regarding their functionalities and effective structural properties which has made them attractive and apparent in the biological and biomedical sciences as well as various other disciplines of science including physics and chemistry [2]. Nanoparticles are categorized into various types depending on their morphological characteristics and physico- 
chemical properties, of which size is the main consideration. Based on their nature, they can be polymeric, carbon-based, lipid-based, ceramic or metallic [3]. Among all of these, metallic nanoparticles including those employing zinc, silver, gold, magnesium dioxide, cadmium, titanium, iron oxide etc have been well known for their peculiar properties owing to size and shape [4]. Among all of the metallic nanoparticles reported to date, silver nanoparticles (AgNPs) display excellent properties with regard to physico-chemical as well as biological aspects [5]. These are widely considered as being one of the most capable metallic nanoparticles that have demonstrated good catalytic as well as conductance phenomena which have proven to be especially advantageous in the fields of photochemistry, biomedicine and agriculture [6].

For the synthesis of AgNPs, diverse methodologies involving chemical, physical and biological processes have been employed [7]. Use of expensive, hazardous and noxious materials in physical and chemical methods have made them unreliable for use [1]. Exploitation of naturally occurring living entities (plants, microbes, algae etc) for synthesizing AgNPs has proven helpful to prevail over these problems efficiently. Among these, biologically active units such as plants containing naturally occurring metabolites provide high reducing and capping capabilities upon which working potential and properties of synthesized nanoparticles rely, and so have been the best choice for silver nanofabrication $[8,9]$.

Various components of medicinally active plants including flowers, rhizome, peel, leaves, etc can be utilized as a source of extraction for silver nanofabrication [10]. Synthesis of AgNPs has previously been reported for numerous plants including, for instance, Plumeria alba (frangipani) flower extract, Azadirachta indica leaf extract,
Boerhaavia diffusa whole plant extract as well as peel extracts of Musa paradisiacal, Citrus sinensis and Eucalyptus hybrid [7, 11, 12]. Research has established that Aloe vera as a medicinally active plant having multitask attributes regarding health care problems plays a pivotal role as an anti-inflammatory and anti-bacterial agent $[13,14]$. Ranunculus paludosus, a perennial plant and Matthiola incana, an ornamental plant, also potentially possess potent biocidal activity which has never been tested earlier, to the best of our knowledge. Keeping in view the significance of these three plants, present study was carried out for fabrication of AgNPs from peel of Aloe vera and fresh flowers of Ranunculus paludosus and Matthiola incana. Furthermore, characterization and evaluation of their antibacterial potential against clinically isolated MDR pathogens was successfully achieved.

\section{Materials and Methods}

\section{Preparation of plant extracts}

Fresh Aloe vera plants ware collected from Madinah nursery located at Muzaffarabad Sher Shah Road, Multan while fresh flowers of Ranunculus paludosus and Matthiola incana were collected from Baaghbahara nursery near Northern By-pass, Multan. These samples were taken in sterile plastic bags and washed using double distilled water so as to remove contaminants or debris, if any. Leaves of Aloe vera were peeled off carefully to discard the gel portion subsequent to which peel was oven dried and converted to fine dry powder. $5 \mathrm{~g}$ fine powder was mixed in $100 \mathrm{ml}$ of distilled water, ethanol and methanol in separate flasks, respectively. This solution was mixed by using shaking incubator at $37^{\circ} \mathrm{C}$ and $120 \mathrm{rpm}$ for 24 hours, and filtered later on. Petals of Ranunculus paludosus and Matthiola incana were dried at room temperature, converted into thin paste and then mixed with distilled water in ratios 1:3, 1:4 and 1:5 in separate flasks, respectively. Solution was then heated 
at magnetic stirrer and later on cooled down at room temperature and filtered.

\section{Selection of clinical isolates}

Cultures of MDR pathogenic bacteria were obtained from Diagnostic Laboratory of Nishtar Hospital, Multan to evaluate the antimicrobial potential of synthesized AgNPs. These included Pseudomonas aeruginosa, Proteus vulgaris, Escherichia coli and Staphylococcus aureus which were used for all sources of nanoparticles, in general. Additionally, antibacterial potential of Aloe vera was assessed against Klebsiella pneumoniae and that of Ranunculus paludosus and Matthiola incana was evaluated against Salmonella enterica and Enterobacter spp., specifically.

\section{Biosynthesis of silver nanoparticles}

For synthesizing AgNPs, silver nitrate solution was prepared by addition of $0.0102 \mathrm{~g}$ of silver nitrate to $12 \mathrm{ml}$ of dist. water which was subsequently added to crude extracts of Aloe vera peel and flowers of Ranunculus paludosus and Matthiola incana. Change in color from green to dark brown (Aloe vera and Ranunculus paludosus) or dark purple (Matthiola incana) marked the synthesis of AgNPs which were stored at $2^{\circ} \mathrm{C}$ until further use.

\section{Characterization of silver nanoparticles}

Reduction of $\mathrm{Ag}^{+}$to $\mathrm{Ag}^{\circ}$ was observed by measuring the $\mathrm{UV}$-isible spectrum within the range of $400-800 \mathrm{~nm}$ at a resolution of $10 \mathrm{~nm}$ using the UV-Visible spectrophotometer. Crude extracts were used as control. Fourier transform infrared (FTIR) spectroscopy was done to evaluate characteristic phytochemicals in each flower extract. The role of flower extracts as reducing and capping agents as well as presence of vital groups was confirmed by FTIR analysis in transmittance mode, over the range of 5004000 wave number $\mathrm{cm}^{-1}$.
Antibacterial activity of crude extracts and synthesized silver nanoparticles

For the estimation of antibacterial activity of crude extracts and synthesized AgNPs, Kirby-Bauer method was used. Wells in Müller-Hinton agar plates were filled with $20 \mu \mathrm{g}$ of crude extracts and synthesized nanoparticles of Aloe vera peel, and flowers of Ranunculus paludosus and Matthiola incana separately. Plates were then incubated at $37^{\circ} \mathrm{C}$ for 24 hours.

Synergistic activity of silver nanoparticles with antibiotics

Synergistic activity of biosynthesized AgNPs was estimated with selected antibiotics including Ampicillin, (AMP, 10 $\mu \mathrm{g}$ ),

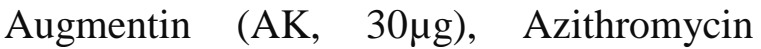

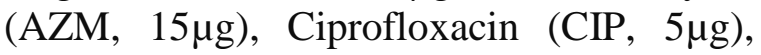
Amikacin (AMC, 30 $\mu$ g), Levofloxacin

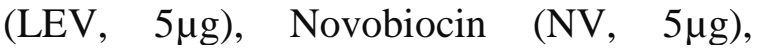
Tetracycline (TE, 30 $\mu \mathrm{g}$ ) and Vancomycin (VA, $5 \mu \mathrm{g}$ ). For this purpose, well diffusion method was employed. To each well, $20 \mu 1$ of AgNP solution was added, approximately and selected antibiotic disks were soaked in these wells. Plates were then incubated at $37^{\circ} \mathrm{C}$ for 24 hours. All analyses were performed in triplicates to avoid false positive or negative results and to minimize human error.

\section{Results}

Fabrication of silver nanoparticles

Confirmation of AgNP synthesis from Aloe vera peel, as well as Ranunculus paludosus and Matthiola incana flowers was done by visual analysis separately. When colorless silver nitrate solution was added to greenish crude extract of Aloe vera, a brown colored suspension was produced while the light yellowish green crude extract of Ranunculus paludosus turned into dark brown suspension. Similarly, Matthiola incana floral extract changed from light purple to dark purple indicating the presence of AgNPs (Fig. 1). 

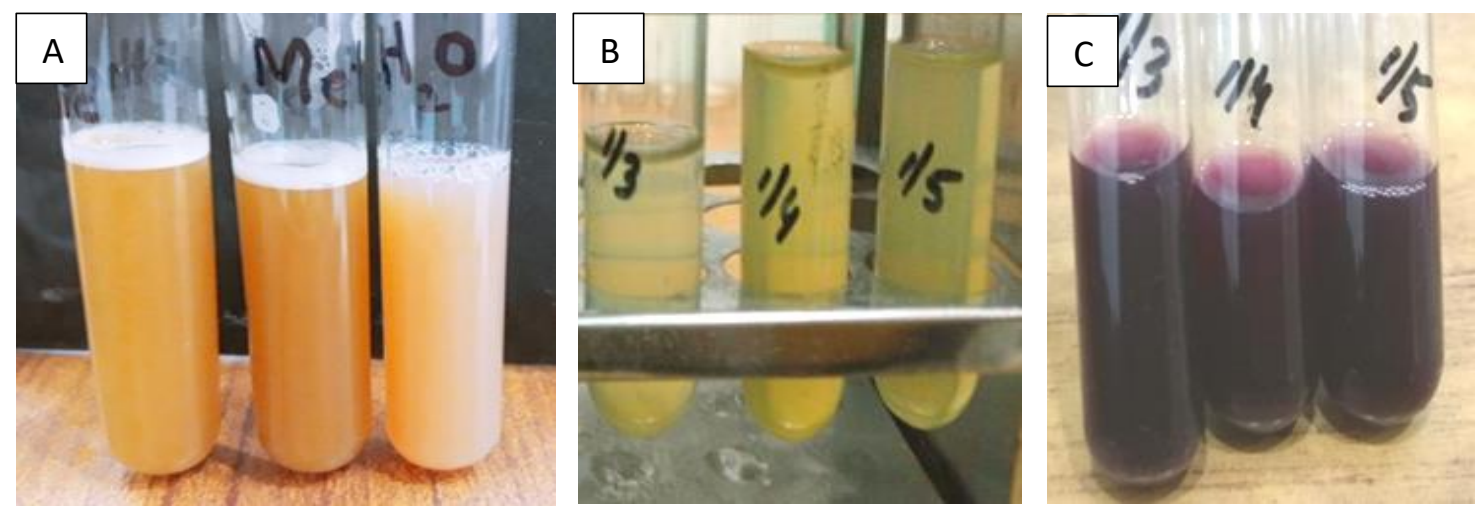

Figure 1. Visual analysis of nanoparticle synthesis for extracts of (A) Aloe vera peel (B) Ranunculus paludosus flowers (C) Matthiola incana flowers

Spectroscopic analysis of silver nanoparticles

For UV-visible spectroscopy, both the diluted and concentrated solutions were used. Maximum peak was shown by diluted sample and absorbance for both flower extracts was between 1.0 and 1.5 in the range of 400450nm, confirming the presence of AgNPs (Fig. 2). FTIR bands for Matthiola incana were observed in different regions including the most broadened absorbance band at $3442.22 \mathrm{~cm}^{-1}$ (Fig. 3). The peak detected at $3442.22 \mathrm{~cm}^{-1}$ represented $\mathrm{O}-\mathrm{H}$ group because

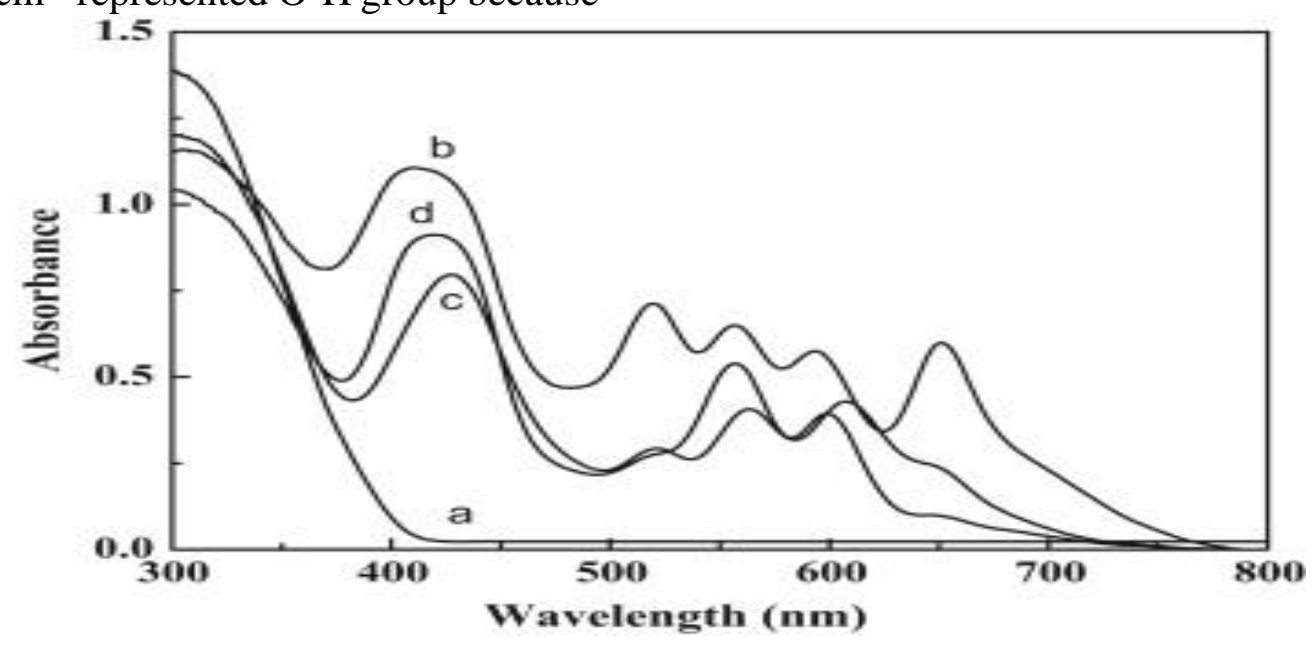

Figure 2. UV-Visible absorption spectrum for silver nanoparticles of (a) concentrated flower extract of Matthiola incana (b) diluted flower extract of Ranunculus paludosus (c) diluted flower extract of Matthiola incana (d) concentrated flower extract of Ranunculus paludosus. 


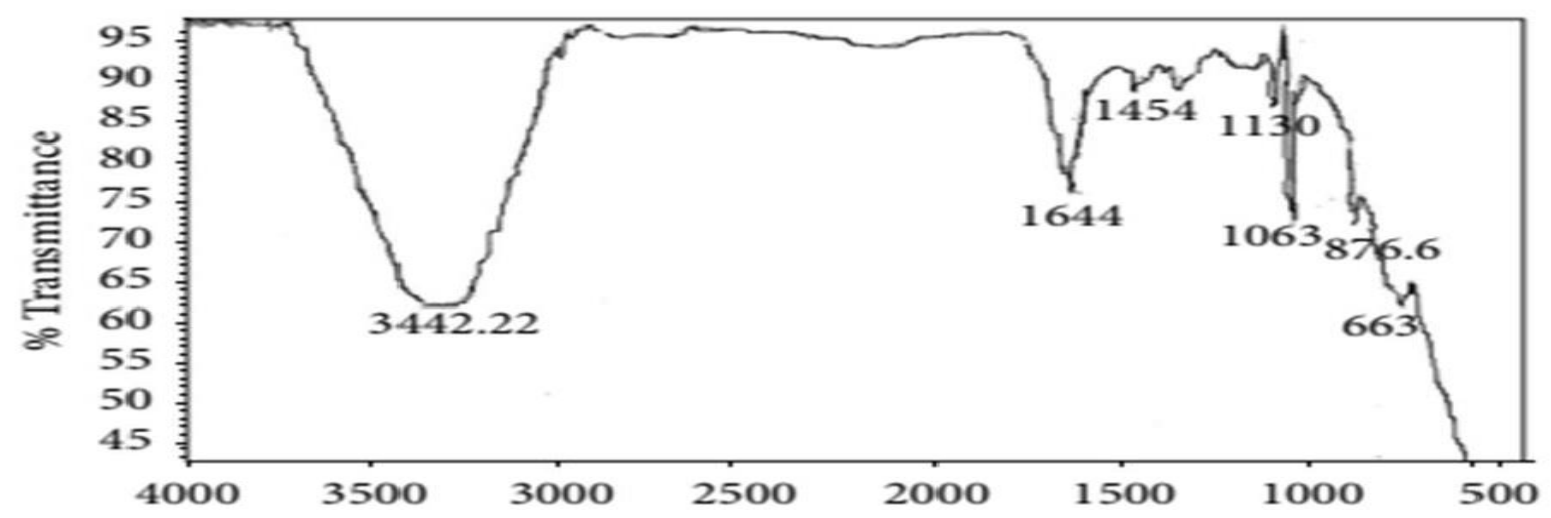

Figure 3. FTIR spectrum recorded for Matthiola incana showing the presence of phytochemicals

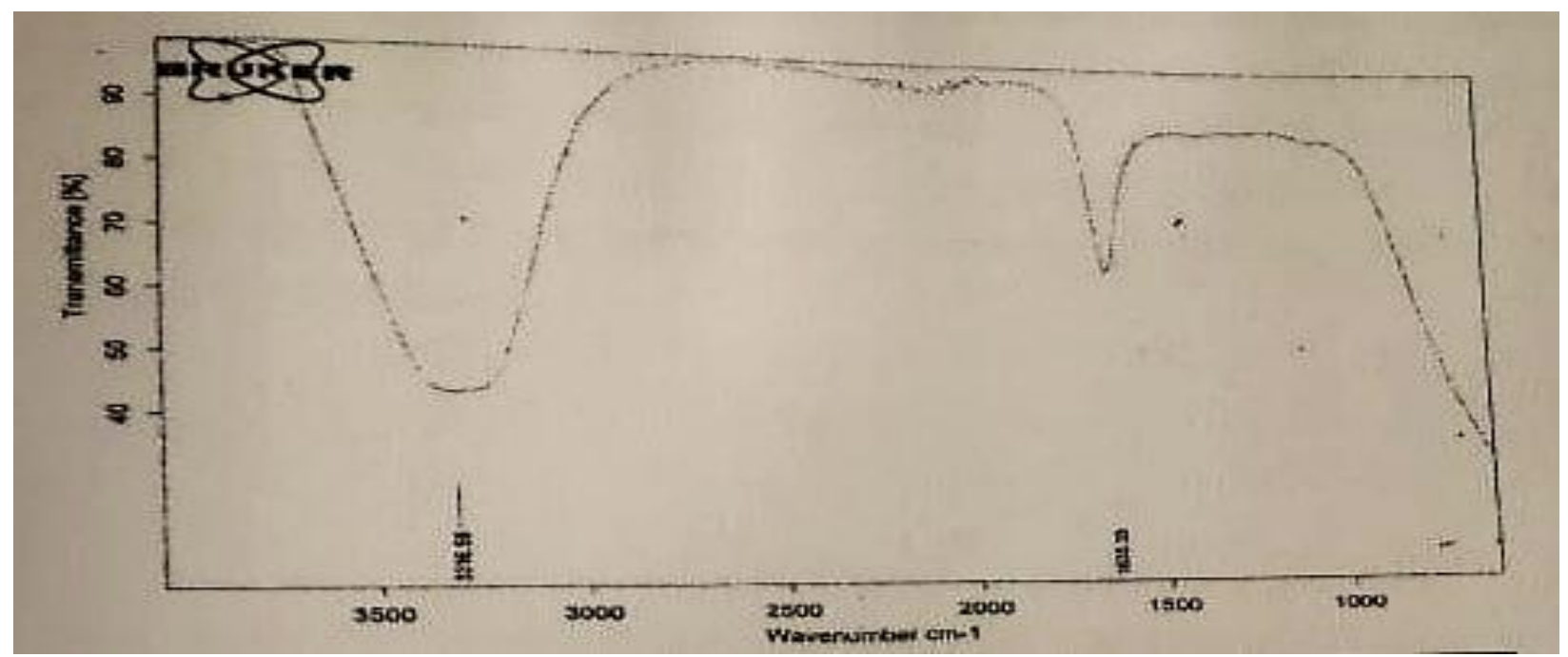

Figure 4. FTIR spectrum recorded for Ranunculus paludosus showing the presence of phytochemicals

Antibacterial activity of crude extracts and synthesized silver nanoparticles

After incubation, no zones of inhibition were observed for the crude extracts of either the Aloe vera peel or flowers of Ranunculus paludosus and Matthiola incana. Apparently, this indicated the low biocidal effect of crude extracts against MDR pathogenic bacteria. For Aloe vera, aqueous extract containing AgNPs exhibited antibacterial activity against E. coli, Staph. aureus and Proteus vulgaris, methanolic extract against $E$. coli, and ethanolic extract against all selected pathogens (Table 1). For Ranunculus paludosus and Matthiola incana, the most concentrated extract proved to be the most effective and results are included only for the nanoparticles synthesized from it. As shown in (Table 2), AgNPs synthesized from Ranunculus paludosus floral extract were the most effective against $P$. aeruginosa and Proteus vulgaris while those produced using Matthiola incana floral extract proved to be the most efficacious against $P$. aeruginosa and Salmonella enterica. 
Table 1. Mean zones of inhibition produced by synthesized silver nanoparticles of Aloe vera peel

\begin{tabular}{|c|c|c|c|c|c|c|c|c|c|c|}
\hline Test Organism / Extract & $\begin{array}{c}\text { No antibiotic } \\
(\mathrm{mm})\end{array}$ & $\begin{array}{l}\text { AMC } \\
(\mathbf{m m})\end{array}$ & $\begin{array}{l}\text { AUG } \\
(\mathbf{m m})\end{array}$ & $\begin{array}{c}\mathrm{TE} \\
(\mathbf{m m})\end{array}$ & $\begin{array}{l}\text { AZM } \\
(\mathbf{m m})\end{array}$ & $\begin{array}{l}\text { AMP } \\
(\mathbf{m m})\end{array}$ & $\begin{array}{c}\text { CIP } \\
(\mathbf{m m})\end{array}$ & $\begin{array}{c}\mathrm{NV} \\
(\mathbf{m m})\end{array}$ & $\begin{array}{l}\text { LEV } \\
(\mathbf{m m})\end{array}$ & VA (mm) \\
\hline \multicolumn{11}{|c|}{ E. coli } \\
\hline Aqueous & 12 & 13 & 13 & 20 & 20 & 13 & 17 & -- & -- & -- \\
\hline Methanolic & 12 & -- & 20 & -- & -- & -- & 19 & 16 & 19 & 14 \\
\hline Ethanolic & 10 & --- & 20 & 17 & 17 & 10 & 14 & -- & -- & -- \\
\hline \multicolumn{11}{|c|}{ Staph. aureus } \\
\hline Aqueous & 12 & 13 & 13 & 20 & 20 & 13 & 17 & & & \\
\hline Methanolic & -- & -- & 20 & -- & -- & -- & 10 & 16 & 18 & 10 \\
\hline Ethanolic & 8 & 12 & Clear & Clear & Clear & $15 \mathrm{~mm}$ & Clear & -- & -- & -- \\
\hline \multicolumn{11}{|c|}{ P. aeruginosa } \\
\hline Aqueous & -- & 13 & 12 & 23 & 15 & 11 & 21 & -- & -- & -- \\
\hline Methanolic & -- & -- & 20 & -- & -- & -- & 19 & 16 & 19 & 14 \\
\hline Ethanolic & 10 & 12 & 20 & 16 & 14 & 12 & 15 & -- & -- & -- \\
\hline \multicolumn{11}{|c|}{ K. pneumoniae } \\
\hline Aqueous & -- & 13 & 10 & 23 & 15 & 11 & 21 & -- & -- & -- \\
\hline Methanolic & -- & -- & 20 & -- & -- & -- & 19 & 20 & 19 & 19 \\
\hline Ethanolic & 15 & 10 & 24 & 13 & 15 & 10 & 15 & -- & -- & -- \\
\hline \multicolumn{11}{|c|}{ Proteus vulgaris } \\
\hline Aqueous & 12 & 13 & 15 & 20 & 20 & 13 & 17 & -- & -- & -- \\
\hline Methanolic & -- & -- & 14 & -- & -- & -- & 19 & 10 & 15 & 10 \\
\hline Ethanolic & 12 & 10 & 24 & 18 & 10 & 10 & 19 & -- & -- & -- \\
\hline
\end{tabular}

$\mathrm{AMC}=$ Amikacin, $\mathrm{AUG}=$ Augmentin, $\mathrm{AMP}=$ Ampicillin, $\mathrm{TE}=$ Tetracycline, $\mathrm{AZM=Azithromycin,} \mathrm{AMP}=\mathrm{Ampicillin}, \mathrm{CIP}=$ Ciprofloxacin, $\mathrm{NV}=\mathrm{Novobiocin}$, LEV=Levofloxacin, VA=Vancomycin 
Table 2. Mean zones of inhibition produced by synthesized silver nanoparticles of Matthiola incana and Ranunculus paludosus floral extracts

\begin{tabular}{|c|c|c|c|c|c|c|c|c|c|c|}
\hline $\begin{array}{c}\text { Test Organism / } \\
\text { Extract }\end{array}$ & $\begin{array}{l}\text { No Antibiotic } \\
(\mathbf{m m})\end{array}$ & $\begin{array}{l}\text { AMC } \\
(\mathbf{m m})\end{array}$ & $\begin{array}{l}\text { AUG } \\
(\mathbf{m m})\end{array}$ & $\begin{array}{c}\text { TE } \\
(\mathbf{m m})\end{array}$ & $\begin{array}{l}\mathbf{A Z M} \\
(\mathbf{m m})\end{array}$ & $\begin{array}{l}\mathbf{A M P} \\
(\mathbf{m m})\end{array}$ & $\begin{array}{c}\mathbf{C I P} \\
(\mathbf{m m})\end{array}$ & $\begin{array}{l}\mathbf{N V} \\
(\mathbf{m m})\end{array}$ & $\begin{array}{l}\text { LEV } \\
(\mathbf{m m})\end{array}$ & VA (mm) \\
\hline \multicolumn{11}{|c|}{ E. coli } \\
\hline Matthiola incana & 9.9 & 24 & 19 & 26 & 24 & 23 & 26 & 22 & 24 & 19 \\
\hline Ranunculus paludosus & 7.9 & 22 & 18 & 18 & 19 & 26 & 19 & 18 & 18 & 18 \\
\hline \multicolumn{11}{|c|}{ Staph. aureus } \\
\hline Matthiola incana & 8.2 & 16 & 22 & 25 & 12 & 26 & 16 & 16 & 16 & 22 \\
\hline Ranunculus paludosus & 8.9 & 17 & 18 & 20 & 20 & 22 & 16 & 17 & 24 & 22 \\
\hline \multicolumn{11}{|c|}{ P. aeruginosa } \\
\hline Matthiola incana & 10.3 & 19 & 16 & 18 & 16 & 24 & 18 & 24 & 22 & 16 \\
\hline Ranunculus paludosus & 10.5 & 22 & 18 & 20 & 16 & 24 & 24 & 26 & 22 & 16 \\
\hline \multicolumn{11}{|c|}{ Enterobacter spp. } \\
\hline Matthiola incana & 9.1 & 22 & 22 & 18 & 18 & 24 & 20 & 22 & 24 & 22 \\
\hline Ranunculus paludosus & 8.7 & 22 & 16 & 18 & 16 & 24 & 16 & 20 & 18 & 18 \\
\hline \multicolumn{11}{|c|}{ Salmonella enterica } \\
\hline Matthiola incana & 10.2 & 22 & 24 & 23 & 20 & 26 & 21 & 22 & 16 & 19 \\
\hline Ranunculus paludosus & 10.2 & 16 & 20 & 22 & 24 & 26 & 19 & 19 & 18 & 19 \\
\hline \multicolumn{11}{|c|}{ Proteus vulgaris } \\
\hline Matthiola incana & 8.5 & 22 & 20 & 19 & 18 & 24 & 18 & 19 & 18 & 19 \\
\hline Ranunculus paludosus & 10.5 & 24 & 18 & 19 & 19 & 24 & 19 & 18 & 18 & 19 \\
\hline
\end{tabular}

AMC=Amikacin, AUG=Augmentin, AMP=Ampicillin, TE=Tetracycline, AZM=Azithromycin, AMP=Ampicillin, CIP=Ciprofloxacin, NV=Novobiocin , LEV=Levofloxacin, VA=Vancomycin 
Synergistic activity of silver nanoparticles with antibiotics

In case of Aloe vera peel, AgNPs synthesized from ethanolic extract in synergy with antibiotics AUG, TE, AZM and CIP demonstrated the strongest antibacterial activity against Staph. aureus by clearing its growth completely (Table 1). Against E. coli, aqueous NPs with TE and AZM, as well as methanolic and ethanolic extracts with AUG were the most effective. Ethanolic NPs in combination with AUG produced the best results against $K$. pneumoniae as well as Proteus vulgaris. Aqueous NPs with TE demonstrated the highest activity against $P$. aeruginosa. In terms of floral extracts, it was observed that the antibacterial potential of Ranunculus paludosus and Matthiola incana was markedly enhanced in the presence of antibiotics (Table 2). Specifically, Matthiola incana proved to possess the most robust activity against $E$. coli in combination with $\mathrm{TE}$ and CIP and against Staph. aureus as well as Salmonella enterica in concert with AMP. Likewise, Ranunculus paludosus was described as being the most effective against E. coli as well as Salmonella enterica in combination with AMP, and against $P$. aeruginosa in synergy with NV.

\section{Discussion}

Antibiotic overuse and misuse has intensified the proliferation of MDR pathogens which are now considered an emerging global epidemic to combat which, innovative approaches are obligatory. Many metals, such as silver $(\mathrm{Ag})$, copper $(\mathrm{Cu})$, and zinc $(\mathrm{Zn})$, have long been used to combat bacteria even before the use of antibiotics became widespread [15]. Ag salts have been well recognized for their antimicrobial properties since antiquity, and $\mathrm{Ag}$ was once thought to be the most popular antibacterial and antifungal agent. AgNPs have recently been shown to have strong antibacterial activity against several pathogens, including
Salmonella, Pseudomonas, and Staphylococcus species [16].

The current study aimed at assessing the antibacterial potential of Aloe vera peel extract as well as floral extracts of Ranunculus paludosus and Matthiola incana to accomplish which, AgNPs were synthesized. The color of crude extract of Aloe vera peel changed from light green to dark brown when silver nitrate solution was added to it indicating the reduction of silver nitrate into AgNPs. Previously, Chaudhary et al reported color change from green to yellow while synthesizing zinc oxide nanoparticles using Aloe vera peel [1]. Upon addition of silver nitrate solution, light yellowish green crude extract of Ranunculus paludosus turned into dark brown suspension and that of Matthiola incana turned dark purple from light purple. In another report, Rashid et al described color change from light yellow to dark brown during the synthesis of AgNPs from Balantidium ciliate [17].

To confirm the formation of AgNPs from flower extracts, UV-Visible and FTIR spectroscopy analyses were performed. Due to surface plasmon resonance (SPR), a color change was observed during the formation of AgNPs for a longer reaction time which was the characteristic feature of silver giving maximum absorbance at $425 \mathrm{~nm}$ [18]. Through the action of phytochemicals present in plant extracts, formation of AgNPs occurred by the reduction of silver ions into metallic silver $\left(\mathrm{Ag}^{\circ}\right)$. Color variation can be attributed to variation in particle size and shape [19]. The more intensified color change with time reflects more formation of AgNPs which validated their synthesis. Higher absorbance was observed in case of diluted sample of Ranunculus paludosus which is in accordance with previous studies [20]. SPR absorption band occurs due to presence of free electrons present in metals being the reason for combined vibration of 
metallic nanoparticles' electrons in resonance with a light wave [21].

Infrared spectrum comprises two main regions: fingerprint region and functional group region. The organic compounds give absorption spectra usually in the region of functional group while metals generally give absorption band in the fingerprint region [22]. Formerly, FTIR analysis of nanoparticles synthesized from leaf extracts of Hagenia abyssinica revealed peaks similar to our observations showing the presence of various functional groups such as $-\mathrm{OH}$, $\mathrm{COOH}$, and $-\mathrm{CN}$ groups of secondary amines [23]. Our results were in accordance with this study as manifested by different peaks indicating the presence of functional groups. The AgNPs of Aloe vera demonstrated the largest inhibition zones against Staph. aureus and the smallest inhibition zones against Proteus vulgaris. The synthesized AgNPs showed larger zone of inhibition against Staph. aureus than gram-negative bacteria possibly due to differences in their cell wall composition. For floral extracts, the highest concentration produced the most remarkable results against all isolates because concentration of extract is a critical determinant of optimal yield of AgNPs due to effect on availability of biomolecules [24]. These observations reinforced that synthesized AgNPs possess excellent antibacterial activity [25]. Antimicrobial activity of synthesized AgNPs from Aloe fleurentiniorum extract against Staph. aureus and $E$. coli has also been reported previously [26]. On the contrary, decrease in biocidal action of zinc oxide nanoparticles against pathogenic bacteria when combined with antibiotics has been reported due to disruption of antibiotic structural features by zinc oxide nanoparticles [1]. Synergistic activity of AgNPs with antibiotics against pathogens including Staph. aureus, E. coli and $P$. aeruginosa by means of another plant source (Murrayakoenigii spp.) has also been described previously [12]. AgNPs have been reported to possess the potential to arrest the multiplication cycle of many of the microbes [27]. Together, these findings emphasize the fact that the efficacy of antibiotics can be improved enormously by combining them with nanofabricated silver particles from biological sources.

\section{Conclusion}

A critical requirement in the discipline of nanotechnology is development of dependable as well as eco-friendly processes to synthesize nanoparticles. Here, antibacterial efficacy of silver nanoparticles synthesized using a simple, biological approach involving reduction of silver nitrate solution has been reported. Biologically synthesized silver nanoparticles possess the potential to be of enormous usage in medical sciences due to their potent antimicrobial potential as evidenced by persuasive antibacterial potential of Aloe vera, Ranunculus paludosus and Matthiola incana. In the present era of growing antibiotic resistance, this bio-friendly and economical approach seems highly promising necessitating further research in this area.

\section{Authors' contributions}

Conceived and designed the experiments: $U$ Batool, N Jabbar \& I Arooj, Performed the experiments: U Batool \& N Jabbar, Analyzed the data: U Batool, N Jabbar \& I Arooj, Contributed materials/ analysis/ tools: MS Rafique \& S Shaheen, Wrote the paper: U Batool, N Jabbar, I Arooj \& S Shaheen.

\section{References}

1. Chaudhary A, Kumar N, Kumar R \& Salar RK (2019). Antimicrobial activity of zinc oxide nanoparticles synthesized from Aloe vera peel extract. SN Appl Sci 1(1): 136.

2. Ahmadi O, Jafarizadeh-Malmiri H \& Jodeiri N (2019). Optimization of processing parameters for hydrothermal silver nanoparticles synthesis using Aloe vera leaf extract and estimation of their 
physico-chemical and antifungal properties. Z Phys Chem 233(5): 651667.

3. Khan I, Saeed K \& Khan I (2019). Nanoparticles: Properties, applications and toxicities. Arab J Chem 12(7): 90831.

4. Senthilkumar SR \& Sivakumar T (2014). Green tea (Camellia Sinensis) mediated synthesis of zinc oxide nanoparticles and studies on their antimicrobial activities. Int J Pharm Pharm Sci 6(6): 461-465.

5. Tran QH \& Le AT (2013). Silver nanoparticles: synthesis, properties, toxicology, applications and perspectives. Adv Nat Sci: Nanosci Nanotechnol 4(3): 033001.

6. Allafchian AR \& Jalali SAH (2015). Synthesis, characterization and antibacterial effect of poly (acrylonitrile/maleic acid) silver nanocomposite. J Taiwan Inst Chem Eng 57: 154-159.

7. Mata R, Nakkala JR \& Sadras SR (2015). Catalytic and biological activities of green silver nanoparticles synthesized from Plumeria alba (frangipani) flower extract. Mater Sci Eng C 51: 216-225.

8. Ahmad P, Jaleel CA, Salem MA, Nabi G \& Sharma S (2010). Roles of enzymatic and nonenzymatic antioxidants in plants during abiotic stress. Crit Rev Biotechnol 30(3): 161-175.

9. Mittal AK, Chisti Y \& Banerjee UC (2013). Synthesis of metallic nanoparticles using plant extracts. Biotechnol Adv 31(2): 346-356.

10. Roy A (2017). Synthesis of silver nanoparticles from medicinal plants and its biological application: a review. Res Rev Biosci 12(4): 138.

11. Haleemkhan AA, Naseem B \& Vardhini BV (2015). Synthesis of nanoparticles from plant extracts. Int J Mod Chem Appl Sci 2(3): 195-203.
12. Ahmed S, Ahmad M, Swami BL \& Ikram S (2016). A review on plants extract mediated synthesis of silver nanoparticles for antimicrobial applications: a green expertise. $J$ Adv Res 7(1): 17-28.

13. Fields L, Craig WR, Wasileski SA \& Wolfe AL (2019). Effects of Shade on Antibacterial Production in Aloe vera Plants: A Model Course Based Undergraduate Research Experience for First-and Second-Year Chemistry and Biochemistry Students. World 7(4): 248253.

14. Sadoyu S, Rungruang C, Wattanavijitkul T, Sawangjit R, Thakkinstian A \& Chaiyakunapruk N (2020). Aloe vera and health outcomes: An umbrella review of systematic reviews and meta-analyses. Phytother Res 35: 555-576.

15. Lemire JA, Harrison JJ \& Turner RJ (2013). Antimicrobial activity of metals: mechanisms, molecular targets and applications. Nat Rev Microbiol 11(6): 371-384.

16. Zhou Q, Wang T, Wang C, Wang Z, Yang Y, Li P, Cai R, Sun M, Yuan H \& Nie L (2020). Synthesis and characterization of silver nanoparticlesdoped hydroxyapatite/alginate microparticles with promising cytocompatibility and antibacterial properties. Colloids Surf, A: Physicochem Eng Asp 585: 124081.

17. Rashid S, Azeem M, Khan SA, Shah MM \& Ahmad R (2019). Characterization and synergistic antibacterial potential of green synthesized silver nanoparticles using aqueous root extracts of important medicinal plants of Pakistan. Colloids Surf B 179: 317-325.

18. Jacob SJ, Prasad VS, Sivasankar S \& Muralidharan P (2017). Biosynthesis of silver nanoparticles using dried fruit extract of Ficus carica-Screening for its anticancer activity and toxicity in animal 
models. Food Chem Toxicol 109: 951956.

19. Carson L, Bandara S, Joseph M, Green T, Grady T, Osuji G, Weerasooriya A, Ampim P \& Woldesenbet S (2020). Green synthesis of silver nanoparticles with antimicrobial properties using Phyla dulcis plant extract. Foodborne Pathog Dis 17(8): 504-511.

20. Khan M, Tareq F, Hossen M \& Roki M (2018). Green synthesis and characterization of silver nanoparticles using Coriandrum sativum leaf extract. $J$ Eng Sci Technol 13(1): 158-166.

21. Raj S, Mali SC \& Trivedi R (2018). Green synthesis and characterization of silver nanoparticles using Enicostemma axillare (Lam.) leaf extract. Biochem Biophys Res Commun 503(4): 28142819.

22. Khan FA, Zahoor M, Jalal A \& Rahman AU (2016). Green synthesis of silver nanoparticles by using Ziziphus nummularia leaves aqueous extract and their biological activities. J Nanomater 8026843.
23. Murthy HC, Desalegn T, Kassa M, Abebe B \& Assefa T (2020). Synthesis of green copper nanoparticles using medicinal plant hagenia abyssinica (Brace) JF. Gmel. leaf extract: Antimicrobial properties. J Nanomater 3924081.

24. Ibrahim HM (2015). Green synthesis and characterization of silver nanoparticles using banana peel extract and their antimicrobial activity against representative microorganisms. $J$ Radiat Res Appl Sci 8(3):265-75.

25. Guzman M, Dille J \& Godet S (2012). Synthesis and antibacterial activity of silver nanoparticles against grampositive and gram-negative bacteria. Nanomed 8(1): 37-45.

26. Salmen SH \& Alharbi SA (2020). Silver nanoparticles synthesized biogenically from Aloe fleurentiniorum extract: characterization and antibacterial activity. Green Chem Lett Rev 13(1): 1-5. 27. Siddiqi KS, Husen A \& Rao RA (2018). A review on biosynthesis of silver nanoparticles and their biocidal properties. J Nanobiotechnol 16(1): 1-28. 